\title{
Research on Technology of Grid-Connected/Islanded Smooth Switchover of Microgrid
}

\author{
Jiguang Xue ${ }^{1}$, Guoning Lu ${ }^{2}$, Feng $\mathrm{Di}^{3}$, Xianglei Xu ${ }^{4}$, Dongsheng Yang ${ }^{4}$ \\ ${ }^{1}$ Electric Power Research Institute of State Grid Liaoning \\ Electric Power Co.Ltd, Shenyang China \\ ${ }^{2}$ State Grid Shenyang Electric Power Supply Company, Shenyang China \\ ${ }^{3}$ Qingdao Sifang Rolling Stock Research Institute, Qingdao China \\ ${ }^{4}$ College of Information Science and Engineering Northeastern University, \\ Shenyang China \\ yangdongsheng@mail.neu.edu.cn
}

\begin{abstract}
In order to solve the problem of transient oscillation of microgrid during process switching between grid-connected operation and islanded operation, the basic principle of traditional control strategy is analyzed, a novel control structure of smooth switchover for microgrid based on the double negative feedback controller is proposed. Also, to avoid the risk of voltage oscillation caused by the mutual interference of the two controllers in the traditional quasi-synchronization method, an improved quasi-synchronization controller is proposed, which is simpler and easier to implement. Finally, the simulation results verify the validity of the proposed structure. Research results show that the busbar voltage and current oscillation can be solved better with the novel structure, and lay the foundation for smooth switchover.
\end{abstract}

Keywords:microgrid;quasi-synchronization;grid-connectedoperation;islanded operation;smooth switchover

\section{Introductions}

As the problem of environment pollution and energy crisis becoming prominent increasingly in today's society, the clean and renewable distributed generation (DG) has become the focus of the world. But due to the intermittent nature of distributed power supply, which leads to DG difficult to get grid-connected in large-scale[1-4]. Microgrid technology is one of the effective ways to solve the problem.Microgrid can operate both in grid-connected operation and off-gridoperation[5-7].

Because the transient oscillation of switching process will affect the power supply of local load, and even cause switchover failure, how to realize smooth switchover of microgrid is one of the key issues of researchers[8-10].

In this paper, key technology of grid-connected/islanded smooth switchover will be discussed based on master-slave microgrid.Aiming at the problems existed in the smooth switching process of master-slave microgrid, literature [11] analyzes the factors of transient oscillation caused by switchover and put forward the corresponding smooth switchover control strategies, but ignores the suppression method of the corresponding transient fluctuation;literature [12] presents a smooth switchover control strategy, but the results of the experiments show that in the switching process, bus voltage of microgrid still had transient impact, and reached islanding protection conditions of the system, which may lead to system crash;literature [13] adopts the voltage and current weighted control algorithm, to achieve a seamless handover,but ignores when the capacity of the 
main control unit is not sufficient to preserve microgrid power demand, using the control strategy only can not realize the smooth switching of operation state.

Therefore, in this paper, based on the analysis of basic structure and control methods of the master-slave microgrid, an improved controller is puts forward, which can ensure the inner current loop reference value tamed between the switching processes, and prevent bus voltage and current appear large range of oscillation in the process. Then, Secondly, a quasi-synchronization method which is suitable for microgrid is proposed to ensure the accuracy of voltage amplitude, frequency, and phase in synchronization process.

\section{Microgrid Structure and Control Strategy}

\subsection{Structure of Microgrid}

In this paper, the structure of the microgrid system is shown in Fig.1, where all the distributed generations are connected to the AC bus through the three-phase inverter. The microgrid system is connected to the public power grid by the static switch (STS). When the microgrid works in grid-connected mode, the distributed generations and the public power grid work together for the local load. When distributed power supply is more than the load required, the microgrid can transport excess power to the grid. When fault happens in public grid or planned island occurs, the STS will be disconnected and the microgrid will work in the off-grid mode.Then, the distributed generations and energy storage system will supply the power for the local load.

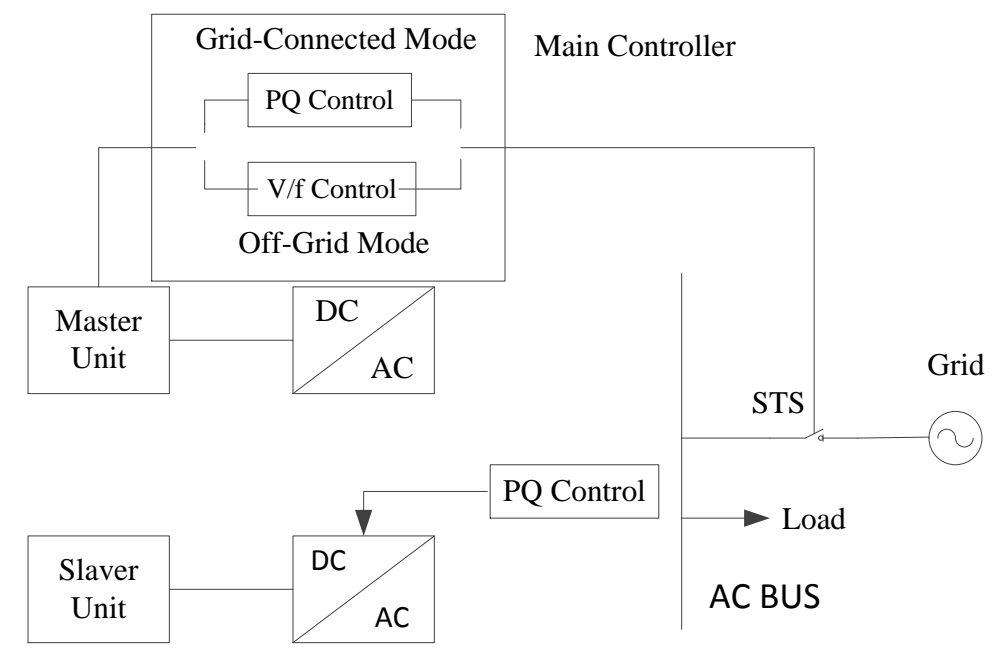

Figure. 1.The Structure of the Microgrid System

For the master-slave microgrid, the main control unit is usually a controllable power supply, such as a micro gas turbine, power conversion system (PCS), diesel generator, etc. When operates in grid-connected mode, both master unit and the slave units adopt the constant power control $(P Q)$; when operates in off-grid mode, master unit switches to the control of constant voltage and constant frequency $(V / f)$, providing voltage and frequency for the slave units, the slave unit still using $P Q$ control. As the control of power conversion system is flexible and active/reactive power regulation is convenient, it is generally chosen as the master unit, and its main circuit structure is shown in Fig.2. In which the main controller realizes the island detection and carries on the control algorithm to switch and the static switch control. 


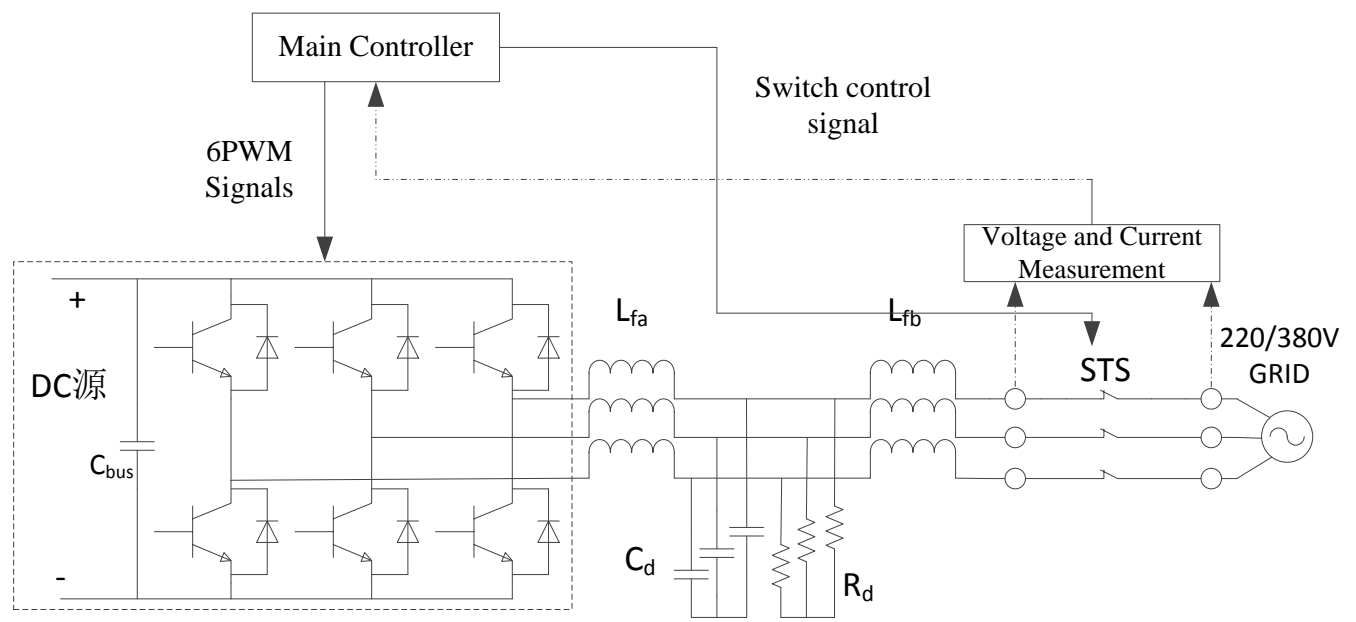

Figure 2.Main Circuit Structure of PCS

\subsection{Control Strategy of Master Unit}

The switchover of the control strategy of master unit is the key problem of the research on smooth switchover of microgrid. Therefore, this paper mainly studies the control strategy of the master unit.

2.2.1 PQ Control Strategy: When operates in grid-connected mode ,the master unit is running in $P Q$ mode.In this mode, the voltage and frequency reference is provided by the grid, $d$ axis orientation in the direction of grid voltage vector in $d q$ rotating coordinate system. Then, the fundamental component of the grid,the converter output current and converter output voltage has the following relationship (ignoring the filter capacitor $C d$ ):

$$
\left\{\begin{array}{l}
e_{d}=u_{d}-\omega L i_{q}+L \frac{d i_{d}}{d t} \\
e_{q}=\omega L i_{d}+L \frac{d i_{q}}{d t}
\end{array}\right.
$$

The $e_{d}$ and $e_{q}$ are the $\mathrm{d}$ axis and $q$ axis components of the converter output voltage, $u_{d}$ is $d$ axis component of the grid voltage, $\omega$ is the reference angular frequency, $L$ is the filter inductance $\left(L=L_{f a}+L_{f b}\right)$, as shown in Fig.2, the $P Q$ control structure diagram shown in Fig. 3. 


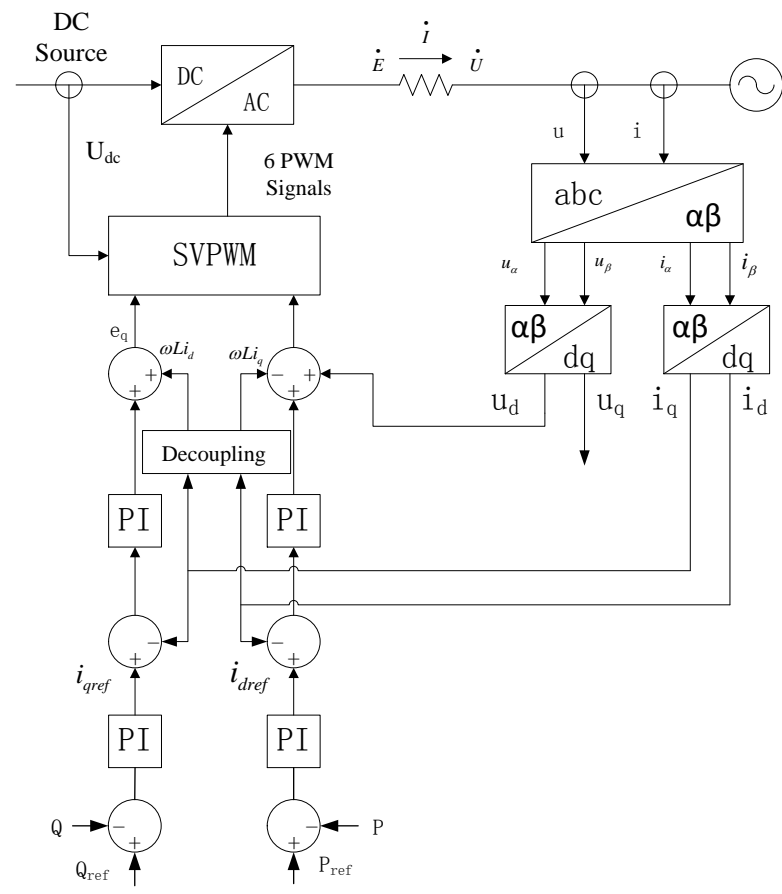

Figure 3.PQ Control Structure Diagram

2.2.2 V/f Control Strategy: When the microgrid is running in the off-grid mode, the master unit adopts $V / f$ control to provide voltage amplitude and frequency reference for the slaver unit. $V / f$ control is a voltage and current double closed-loop controlling method. The output of the voltage loop is given as a reference to the current loop. The control structure is shown in Fig.4, and the current loop of the current loop is completely consistent with the $P Q$ control strategy as shown in Fig.3.

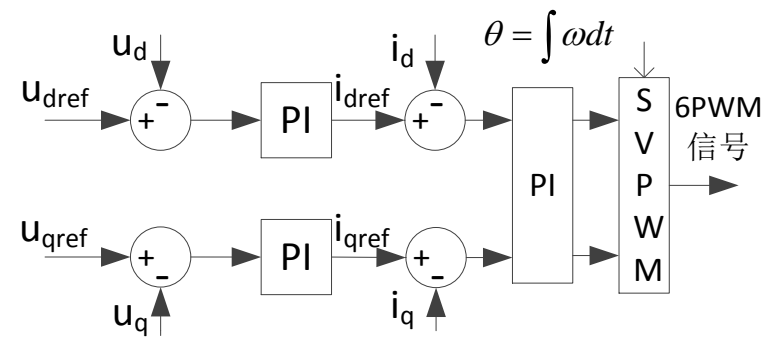

Figure. 4. V/f Control Structure

In practice, the reference values of the voltage outer loop $d$ and $q$ axis are respectively:

$\left\{\begin{array}{l}u_{\text {dref }}=U_{0} \\ u_{\text {gref }}=0\end{array}\right.$

\section{Modified Controller based on Double Negative Feedback}

When the microgrid operation mode is switched, the control strategy of the master unit needs to be switched between $P Q$ control and $V / f$ control. When the master unit switches from the $P Q$ control to the $V / f$ control, the current loop reference value is supplied by the power loop switch to the voltage loop supply. The inconsistency 
between the current reference values in different modes will result in the system transient. Because of in $V / f$ mode the output of voltage loop PI controller need to be regulated from zero to the steady state value, which means after operation mode switching current reference value will mutate to zero, and which led to the bus bar voltage of microgrid dips. Similarly, when the public grid returns to normal and microgrid reconnects to the grid, same problem will happen. This will not only make the power conversion system get a big impact, but will affect the stability of the microgrid bus voltage, threaten security and stable operation of the system. In order to realize the smooth switching of the system, this paper presents a modified controller structure based on double negative feedback, as shown in Fig.5.Due to the current inner loop of $P Q$ control strategy and $V / f$ control method are completely consistent,and in order to ensure the output of the current loop can realize smooth transition in the process of switchover, the control structures have a current loop.

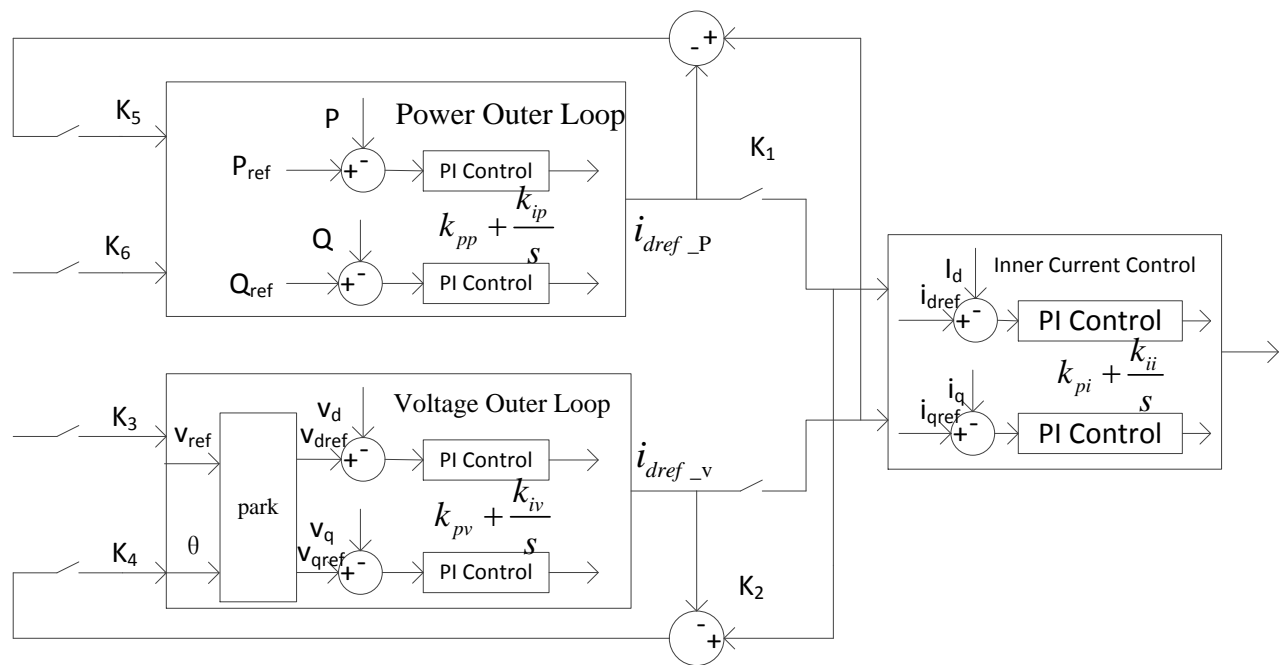

\section{Figure 5. Modified Controller based on Double Negative Feedback}

Among them, the logic control switch $K_{1}-K_{6}$ need to be controlled reasonably, when $P Q$ control is adopted, $K_{1}, K_{4}, K_{6}$ closed, $K_{2}, K_{3}, K_{5}$ open; when $V / f$ control is adopted, $K_{2}, K_{3}$, and $K_{5}$ closed, $K_{1}, K_{4}, K_{6}$ keep open.And logic switch need to be switched along with the control strategy of master unit.

a. When operates in grid-connected mode, master unit adopt $P Q$ control, $K_{l}, K_{4}$ and $K_{6}$ are closed.

In grid-connected mode, $d$ axis reference value of current inner loop $i_{d r e f}$ is equal to $i_{\text {dref_P }}$. The control structure takes power outer loop output of $P Q$ controller and voltage outer loop output of $V / f$ controller as a negative feedback and the result is the input of $V / f$ controller voltage loop. After adjusting by the PI controller, the output of the $V / f$ control voltage outer loop is:

$i_{d r e f_{-} \mathrm{v}}=\left(k_{p v}+\frac{k_{i v}}{s}\right)\left(i_{d r e f_{-} \mathrm{P}}-i_{d r e f_{-} \mathrm{v}}\right)$

Easy to know that the output of $V / f$ control voltage loop $i_{\text {dref- } V}$ can follow the output of the $P Q$ controller $i_{\text {dref }-P \text {. }}$.

b. Grid-connected mode switch to off-grid mode, master unit switch to $V / f$ control strategy, $K_{2}, K_{3}$ and $K_{5}$ are closed.

At this point, the controller switches, $d$ axis reference value of current inner loop $i_{\text {dref }}$ is equal to $i_{\text {dref }-V}$, the output of the $V / f$ control voltage outer loop is: 


$$
i_{d r e f_{-} \mathrm{v}}=\left(k_{p v}+\frac{k_{i v}}{s}\right)\left(\mathrm{v}_{d r e f}-v_{d}\right)+i_{d r e f \_\mathrm{P}}
$$

The control structure takes voltage outer loop output of $V / f$ controller and power outer loop status as a negative feedback and the result is the input of $P Q$ controller power loop. After adjusting by the $P I$ controller, the output of the $P Q$ control voltage outer loop is:

$i_{\text {dref_P }}=\left(k_{p p}+\frac{k_{i p}}{s}\right)\left(i_{\text {dref_v }}-i_{d r e f_{\_} \mathrm{P}}\right)$

c.Off-grid mode switch to grid-connected mode, master unit switch to $P Q$ control strategy, $K_{1}, K_{4}$ and $K_{6}$ are closed.

At this point, the controller switches, $d$ axis reference value of current inner loop $i_{\text {dref }}$ is equal to $i_{\text {dref }-P}$,

$i_{\text {dref_P }}=\left(k_{p p}+\frac{k_{i p}}{s}\right)\left(P_{r e f}-P\right)+i_{\text {dref_ } v}$

By the above formula: at the moment of operation mode conversion,steady-state output of outer loop is equal, namely the modified controller can ensure reference value of current inner loop keep same before and after the mode switch.And the reference value of current inner loop will take the reference value in the moment before switchover as the initial state of the PI controller, to achieve the smooth transition of the control strategy, prevent mutation of switching transient current loop given signal, and ensure the microgrid operation mode switch smoothly.

\section{Modified Quasi-Synchronization Controller for Microgrid}

Considering the control process of traditional quasi-synchronization controller is complicated, in this section, a modified quasi-synchronization controller for microgrid is proposed.

Quasi-synchronization control including three aspects: voltage amplitude, frequency and phase. It's easy to find that the three control elements all can be reflected in voltage in $d q$ rotating coordinate system. Aiming at each control unit may interfere with each other, we adjust the voltage in $d q$ rotating coordinate system directly to avoid the coordinated scheduling of multiple control units.

From literature [14], we can know that if we get cosine and sine of synchronous rotary angle $\omega t+\theta$ by adaptive notch filter(ANF) and transform original voltage to $d q$ rotating coordinate system, the voltage contains information such as amplitude, frequency and phase. Both controlled quantity of the modified quasi-synchronization controller and $V / f$ controller are voltage in $d q$ rotating coordinate system. So quasi-synchronization control and $V / f$ control can be implemented simultaneously .System oscillation caused by quasi-synchronization controller and $V / f$ controller interference can be avoided as well as the number of control units can be reduced .Modified quasi-synchronization controller structure is shown in Fig. 6.

In modified quasi-synchronization controller, all of the controlled quantity is $D C$ signals in $d q$ rotating coordinate system. Therefore, the three-phase voltage $U_{A}, U_{B}$, $U_{C}$ of microgrid system and three-phase voltage $U_{U}, U_{V}, U_{W}$ of power distribution network must be transformed to $d q$ coordinate system. As shown in Fig.6,take microgrid system as an example, according to literature [14], sine and cosine value of the synchronous rotation angle of bus voltage can be obtained.Then by the means of Park transformation, the voltage in $d q$ rotating coordinate system $U_{M_{-} d}, U_{M_{-} q}$ contains the voltage amplitude, frequency and phase information of microgrid 
system can be obtained. Similarly we can get voltage $U_{G_{-} d} 、 U_{G_{-} q}$ of distribution network system in $d q$ rotating coordinate.

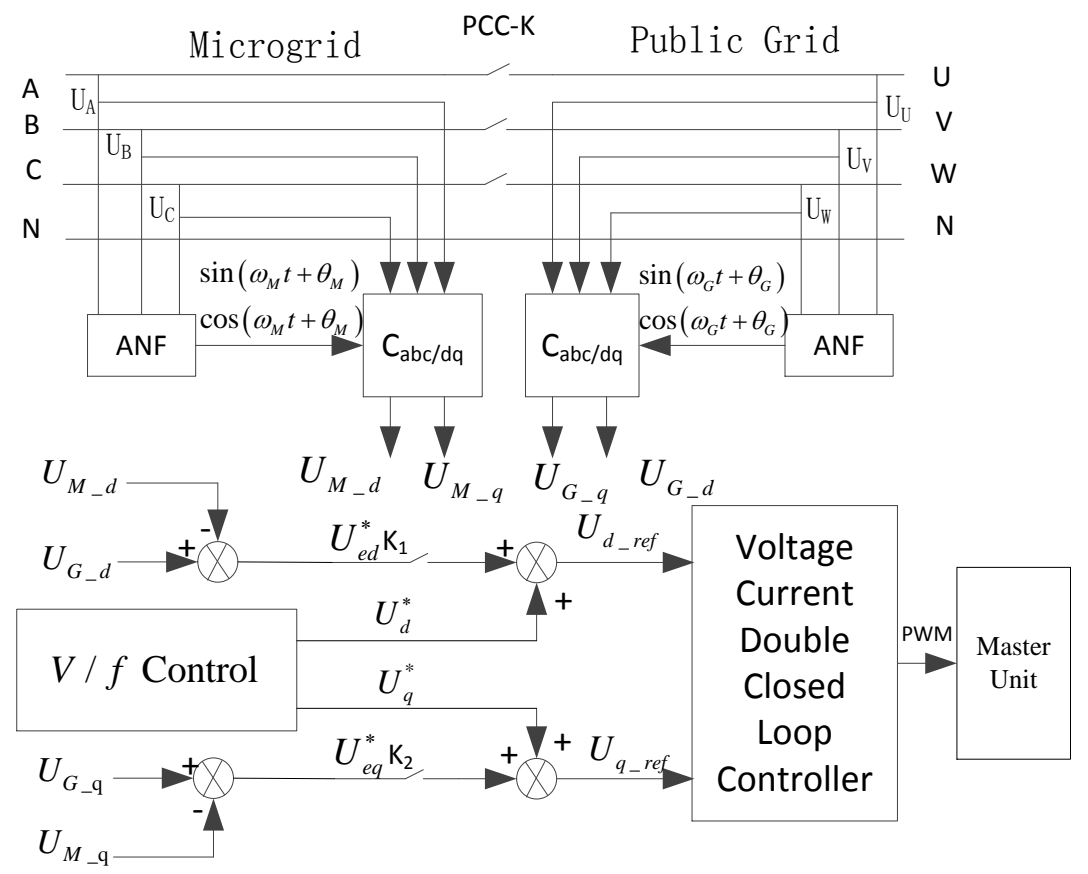

Figure 6. Modifiedquasi-Synchronizationcontrol Block Diagram

In the $d q$ synchronous rotating coordinate system, the voltage reference value of the voltage and current double closed-loop controller are changed to:

$\left\{\begin{array}{l}U_{d_{-} r e f}=U_{G_{-} d}-U_{M_{-} d}+U_{d}^{*} \\ U_{q_{-} r e f}=U_{G_{-} q}-U_{M_{-} q}+U_{q}^{*}\end{array}\right.$

Where $U_{d}^{*}$ and $U_{q}^{*}$ are respectively the $d$ and $q$ axis voltage reference value of voltage loop in off-grid mode.Voltage deviation adjusting signal of the microgrid is included in the $U_{e d}^{*}$ and $U_{e q}^{*}$. The deviation will be adjusted by the voltage and current double closed-loop controller. When the bus voltage of the microgrid meet the condition of quasi-synchronization, dictation is sent out by switching signal control unit and static switch $P C C-K$ is closed. Then the microgrid switches to grid-connected mode. When the synchronization is successful, the power conversion system is switched to $P Q$ control, and the quasi-synchronization controller is out of operation.

\section{The Simulation Results and Analysis}

In order to prove the feasibility of the proposed control structure and quasi synchronization control method in this paper, the simulation is carried out in MATLAB/simulink software. In the simulation, a power converter serves as a master unit and a photovoltaic inverter serves as a slaver unit. The main electrical parameters of the microgrid are shown in Tab. 1.The power distribution of the microgrid is shown in Tab. 2.The power output of each unit is expressed with a negative sign. 
Table 1.The Main Electrical Parameters of the Microgrid

\begin{tabular}{|c|c|c|}
\hline Microgrid & Parameter & Value \\
\hline \multirow{4}{*}{ Master Unit } & Rated Power S/kVA & 50 \\
\cline { 2 - 3 } & Switching Frequency $/ \mathrm{kHz}$ & 10 \\
\cline { 2 - 3 } & Filter Inductance $\left(\mathrm{L}_{\mathrm{fa}} / \mathrm{L}_{\mathrm{fb}}\right) \mathrm{L} / \mathrm{mH}$ & $0.3 / 0.1$ \\
\cline { 2 - 3 } & Filter Capacitor C/uF & 47 \\
\cline { 2 - 3 } & DC Side Voltage $/ \mathrm{V}$ & 800 \\
\hline \multirow{5}{*}{ Slaver Unit } & Rated Power S/kVA & 50 \\
\cline { 2 - 3 } & Switching Frequency $/ \mathrm{kHz}$ & 10 \\
\cline { 2 - 3 } & Filter Inductance $\left(\mathrm{L}_{\mathrm{fa}} / \mathrm{L}_{\mathrm{fb}}\right) \mathrm{L} / \mathrm{mH}$ & $0.3 / 0.1$ \\
\cline { 2 - 3 } & Filter Capacitor $\mathrm{C} / \mathrm{uF}$ & 47 \\
\cline { 2 - 3 } & DC Side Voltage $/ \mathrm{V}$ & 800 \\
\hline & & $380 \mathrm{~V} / 50 \mathrm{~Hz}$ \\
\hline
\end{tabular}

Table 2.The Power Distribution of Themicrogrid

\begin{tabular}{|c|c|c|}
\hline Microgrid & Grid-Connected Mode/kW & Off-Grid Mode/kW \\
\hline Master Unit & $-30 \mathrm{~kW}$ & $-50 \mathrm{~kW}$ \\
\hline Slaver Unit & $-40 \mathrm{~kW},-16 \mathrm{kVar}$ & $-40 \mathrm{~kW},-16 \mathrm{kVar}$ \\
\hline Public Grid & $90 \mathrm{~kW}, 26 / \mathrm{kVar}$ & $90 \mathrm{~kW}, 26 / \mathrm{kVar}$ \\
\hline Load & $-20 \mathrm{~kW},-10 \mathrm{kVar}$ & $0 \mathrm{~kW}, 0 \mathrm{kVar}$ \\
\hline
\end{tabular}

Microgrid operates in grid-connected mode in initial state, public power grid breaks down at $0.1 \mathrm{~s}$, and microgrid switches to off-grid mode. Public power grid failure recovers at $0.3 \mathrm{~s}$; microgrid switches to grid-connected mode again.The simulation results of traditional control structure are shown in Fig.7 and the simulation results of modified control structure is shown in Fig.8. Bus voltage of microgrid, output current of power converter and current of power feeder are shown in the figure top-down.It can be seen from the simulation results, fluctuation of power converter's output current and public grid's output current is small in switchover process with the modified control structure, while the results have more intense jitter and large overshoot with traditional control structure. It is easy to conclude that the modified control structure of this paper has the advantage over the traditional method, and it can realize smooth switchover between operating mode.

Current reference values of $d$ axis with two control structures are shown in Fig.9.It is easy to see that the transient mutation of current reference value is intense with traditional control structure while the current reference value realizes smooth transition with modified structure. The simulation results show the feasibility of the modified control structure.
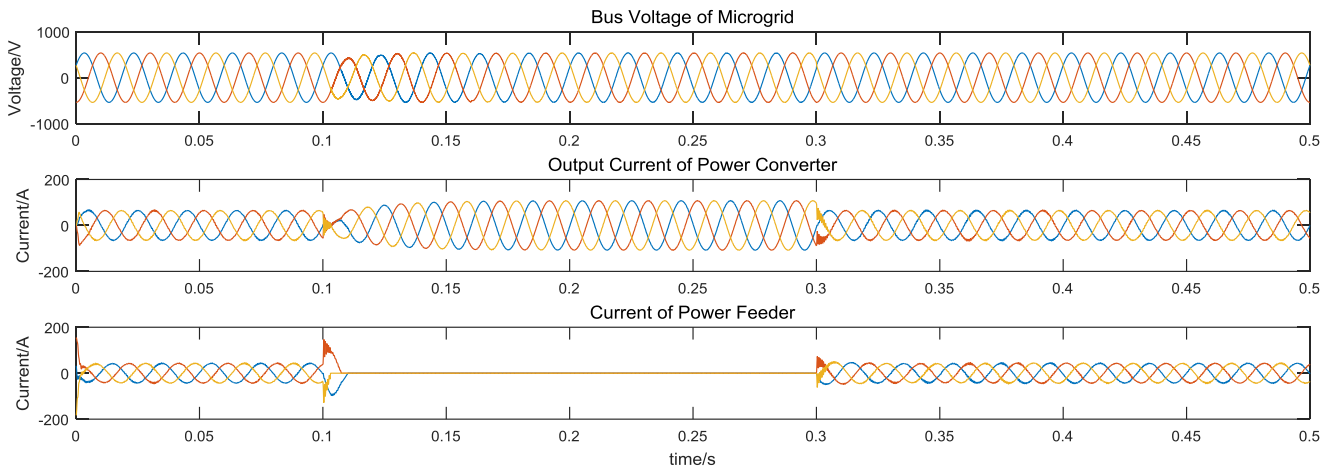

Figure 7.The Simulation Results of Traditional Control Structure 

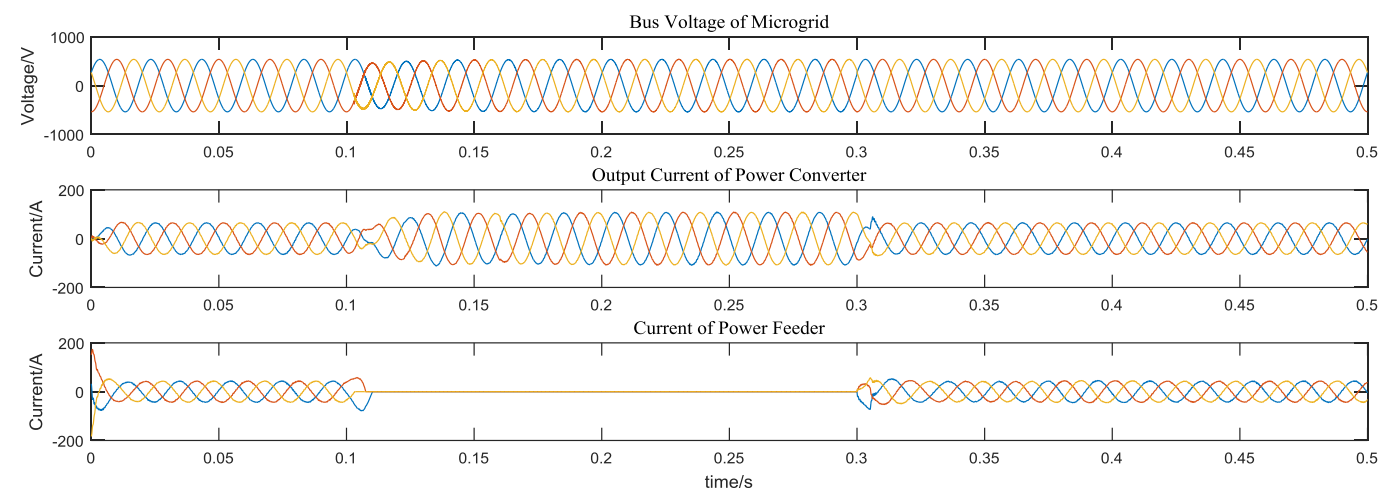

Figure 8.The Simulation Results of Modified Control Structure

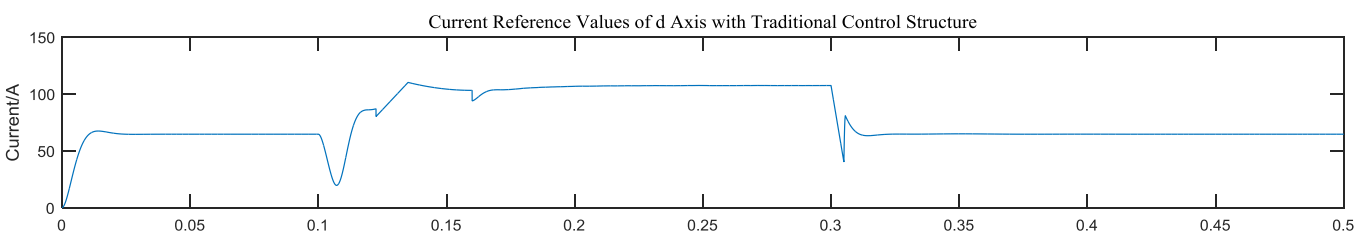

Current Reference Values of $\mathrm{d}$ Axis with Modified Control Structure

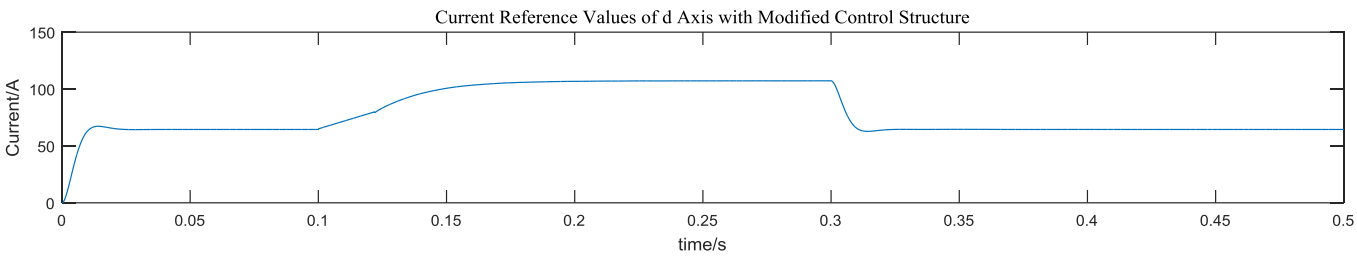

Figure 9.Current Reference Values of d Axis with Two Control Structures

According to the modified quasi-synchronization controller for microgrid proposed in section3, we build the simulation model in the Matlab/Simulink software and to prove the feasibility of it. Microgrid operates in off-grid mode in initial state, power converter receive the dictation of grid connection at $0.05 \mathrm{~s}$. At this time, the quasi-synchronization controller is put into work and track the voltage public grid. When the bus voltage of microgrid meets the condition of quasi-synchronization, microgrid switches to grid-connected operation mode. And power converter switches to $P Q$ control strategy at the same time. The simulation result is shown in Figure. 10.
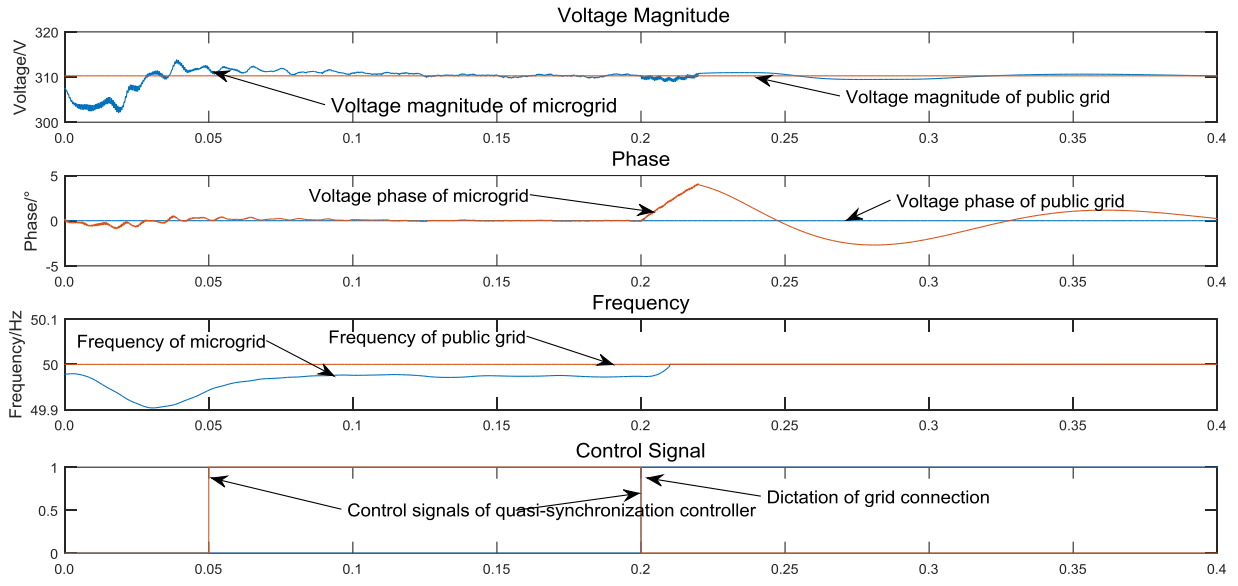

Figure 10.Simulation Waveform of Quasi-Synchronization Control in Microgrid 
The results of the simulation show the voltage, phase and frequency of the microgrid are getting closer to the public grid when the quasi-synchronization controller is put into work. The bus voltage of microgrid meets the condition of quasi-synchronization at $0.2 \mathrm{~s}$, so the STS closes and microgrid switches to grid-connected operation mode.We can find that voltage amplitude, phase and frequency were fluctuant and phase fluctuation is large at $0.2 \mathrm{~s}$ which is due to the switchover of control strategy of power converter.The validity of the proposed controller is verified by simulation.

\section{Conclusions}

Smooth switchover of the microgrid is one of the key issues to ensure the reliable operation.Aiming at the shortcomings of the traditional control structure, this paper puts forward the modified control structure and the modified quasi-synchronization method.And verify the validity of the proposed solutions with the MATLAB/Simulink software.The simulation results show the feasibility and superiority of the proposed structure and quasi-synchronization method.

\section{Acknowledgement}

The work described in this paper was supported by the National Natural Science Foundation of China (61273029), the Natural Science Foundation of Liaoning (2013020037), the Program for New Century Excellent Talents in University of China (NCET-12-0106), and the Fundamental Research Funds for the Central Universities (N130504004).

\section{References}

[1] C. M. Colson, M. H. Nehrir. Comprehensive Real-Time Microgrid Power Management and Control with Distributed Agents [J]. IEEE Transactions on Smart Grid, 4, 617 (2013)

[2] B. Kannan K, S. Kumar R. Power Flow Control and Protection in Micro-Grid[C]. Power and Computing Technologies (ICCPCT), 4, 20 (2013)

[3] Nikkhajoei H, Lasseter R H. Distributed Generation Interface to the CERTS Microgrid [J]. IEEE Transactions on Power Delivery, , 24, 1598 (2009)

[4] J. W. He, Y. W. Li, Bosnjak D, Harris B. Investigation and Active Damping of Multiple Resonances in a Parallel-Inverter-based Microgrid[J]. IEEE Transactions on Power Electronics, ,28, 234 (2013)

[5] T. W. Zheng, L. J. Chen, S. G. Mei. Control Strategy and Application of Power Converter System in Battery Energy Storage System[C]. Innovative Smart Grid Technologies Conference Europe (ISGT-Europe), 1 (2014)

[6] J. Chen, X. Chen, Z. Y. Feng, C. Y. Gong, Y. G. Yan. A Control Strategy of Seamless Transfer between Grid-Connected and Islanding Operation for Microgrid [J], Proceedings of the CSEE, 34, 3089 (2014)

[7] R. Tirumala, N. Mohan, C. Henze. Seamless Transfer of Grid-Connected PWM Inverters between Utility-Interactive and Stand-Alone Modes[C]. 2012 Seventeenth Annual IEEE Applied Power Electronics Conference and Exposition, 1081 (2012)

[8] L. Zeng, J. J Liu. Indirect Current Control based Seamless Transfer of Three-Phase Inverter in Distributed Generation[J]. IEEE Transactions on Power Electronics, 29, 3368 (2014)

[9] Z. Q. Guo, D. S. Sha, X. Z. Liao. Voltage Magnitude and Frequency Control of Three-Phase Voltage Source Inverter for Seamless Transfer[J]. IEEE Transactions on Power Electronics, 7, 200 (2014)

[10] T. ThanhVu, T. W. Chun, H. H. Lee, HeungGeun Kim, EuiCheolNho. PLL-based Seamless Transfer Control between Grid-Connected and Islanding Modes in Grid-Connected Inverters[J]. IEEE Transactions on Power Electronics, 29, 5218 (2014)

[11] D. M. Zhao, N. Zhang, Y. H. Liu, X. Zhang. Syntheticalcontrol Strategy for Smooth Switching between Grid-Connected and Islanded Operation Modes of Microgrid based on Energy Storage System, 37, 301 (2013)

[12] C. S. Wang, X. L. Li, L. Guo. A seamless Operation Mode Transition Control Strategy for a Microgrid based on Master-Slave Control[J]. Science China Technological Sciences, 22, 1644 (2012)

[13] X. H. Wang, C. J. Zhang. Study of Control Strategy for Seamless Transfer of Grid-Connected Distributed Generation Systems[J], Transactions of China Electro technical Society, 27, 217 (2012)

[14] D. Yazdani, M. Mojiri, A. Bakhshai, G. Joos. A Fast and Accurate Synchronization Technique for Extraction of Symmetrical Components [J]. IEEE Transactions on Power Electronics, 24, 674 (2009) 


\section{Authors}
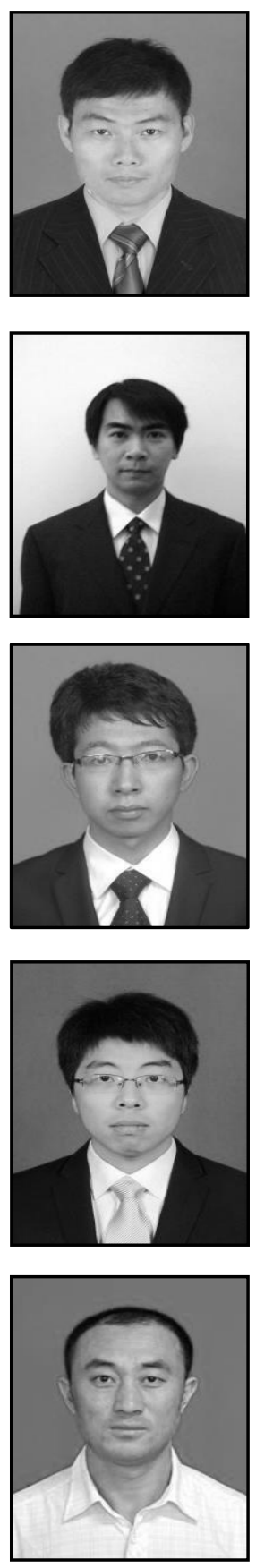

Dongsheng Yang, professor of Northeastern University, he received the $\mathrm{PhD}$ degree in control theory and control engineering from Northeastern University, Shenyang, China. He mainly engaged in new energy, smart grid and power system analysis. 
International Journal of Grid and Distributed Computing

Vol. 9, No. 7 (2016) 